\title{
Analysis on the Problems and Countermeasures of Schools for Migrant Workers' Children
}

\author{
Chun-bo YE
}

Ningbo Dahongying University, Ningbo, Zhejiang, China

Keywords: Problems; Countermeasures; Schools for Migrant Workers' Children.

\begin{abstract}
With the promotion of urbanization, migrant workers are moving to the city, and their children's compulsory education has become increasingly prominent in the inflow area. The article probes into the real dilemma of schools for migrant workers' children, such as insufficient government support, unclear educational objectives, weak teaching staff, rootless students and deficient social support. It is necessary to take some countermeasures to improve school development, including strengthening government support, creating schools' own characteristics, promoting teaching staff, establishing a unified electronic enrollment system and improving off-campus education system.
\end{abstract}

\section{Introduction}

The report of the Nineteenth National Congress of the Communist Party of China has revealed that the priority must be given to national education and emphasized that great efforts have to be made to develop quality education, promote education equity and integrate the development of urban and rural integration, thus every child enjoys fair education. The school for migrant workers' children is an essential way for the children of migrant workers to receive compulsory education. It is time to arouse the concern of the whole society to radically resolve the issue of the schools development for migrant workers' children.

\section{The Problems of Schools for Migrant Workers' Children}

With the government consistent support and efforts, schools for migrant workers' children have made greater achievements than in the past. However, due to the factors, such as history, policy and geographical environment, schools for migrant workers' children fall into an inferior position.

\subsection{Insufficient Government Support}

Lack of Exclusive Policies. Schools for migrant workers' children are relatively weak. It is difficult for them to develop by themselves. They greatly depend on the government support. It is admitted that the government has provided great assistance to schools. However, there are no exclusive policies and regulations to support the school development. Even a small number of policy documents require support and attention to schools. These documents are mostly macro and lack specific operational measures, which results in the poor government enforcement. [1]

Lack of Adequate School Funding. School improvement is a long-term and dynamic process, which requires special development funds. [2] Although the government invests a certain amount of funds and subsidies every year to support the school development, but in view of the different school conditions, the funds required by each school are naturally different. For many relatively weak schools for migrant workers' children, they need funds for the improvement of school conditions, the enhancement of teachers' profession and the construction of school characteristics. However, the existing government input and support efforts still cannot meet the needs of school development.

\subsection{Unclear Educational Objectives}

School Philosophy. The schools for migrant workers' children lack clear guidance in the philosophy of running a school. Most schools for migrant workers' children are located in the urban 
and rural areas of the economically developed counties and cities. Schools are greatly impacted by the modern educational culture of the city. Being in the city for a long time, some migrant workers have not been satisfied with the obtaining learning opportunity of their children. They have a strong desire that their children can get rid of migrant workers' identity and settle down in the city. With parents' urgent desire, the impact of urban culture, and the driving force of economic interests, some schools for migrant workers' children try to train talents to leave the countryside instead of returning to the countryside. The school philosophy greatly strengthens students' yearning for city life and ignores the particularity of migrant children.

Teaching Management. Because of the lack of advanced teaching ideas, the teaching management form of schools for migrant workers' children is relatively simple. Schools regard the management of students as part of the teaching management, instead of taking students as an individual person. Driven by the desire to the city, all the teaching procedures follow the city guide when deciding the teaching content, teaching methods, making curriculum standards and selecting test content. The school curriculum is basically confined to the main courses for the exam. Most schools usually ensure that the non-main courses, such as music, art, physical lesson, information and science are regularly arranged. However, most of the non-main courses are taught by teachers of Chinese and math due to the deficiency of professional teachers. [3] It is difficult to guarantee the teaching quality.

Hardware Facilities. Because of the household registration system and urban-rural dual management system in China, the educational resources distribution in the urban and rural areas is quite imbalanced. Due to the lack of funds, the migrant children's schools struggle in the poverty line, which is manifested by the lack of hardware facilities on campus. Firstly, schools cover a relatively small area. Most schools barely reach the standards of the compulsory education school construction in China. Schools for migrant workers' children are generally leased, including industrial houses, commercial houses and school houses after the relocation of public schools. Secondly, only a few schools own school basketball courts, volleyball courts, parallel bars and horizontal bars and other sports facilities. The teaching facilities such as the computer room, the laboratory, the audio-visual room and so on are scarce as well. With no canteens, some schools' canteens are generally outsourced, which adds the hidden risks. Thirdly, school gardening and window layout are relatively simple and crude. The hardware facilities of schools for migrant workers' children are far behind those of the public schools. Thus, it is difficult for campus culture to play an important role in cultivating students.

\subsection{Weak Teaching Staff}

Teaching staff of schools for migrant workers' children is not optimistic. Firstly, it is difficult to recruit higher quality teachers. In general, teachers of migrant workers' schools mainly come from three parts, the retired teachers in public schools, the outflow teachers in rural schools or urban schools, and graduating students who have not yet found suitable jobs. Teachers' professional level is not satisfactory. Many teachers get the final degrees through correspondence, party school, and TV university. A great many school teachers even lack teachers' qualifications. A large number of teachers own junior titles and still there are many teachers with no titles, far from the standard of the compulsory education school in China. Secondly, migrant school teachers are under flowing condition. Migrant workers' schools fall into the dilemma of the loss of high quality teachers and the instability of teaching staff. As schools are excluded from the government and social security system, teachers generally have low sense of occupational identity. Many teachers regard teaching in migrant workers' schools as short-term behavior rather than long-term career planning. Some even take it as a springboard to enter public schools. Even if in some schools with slightly better conditions, there is still in shortage of backbone and staff leaders. The fatal talent deficiency becomes a stumbling block for the school development. School education runs into a vicious circle because of the constant teacher flowing.

\subsection{Rootless Students}

With the speeding of urbanization process, migrant workers' pure into cities with their children. 
A large number of migrant workers' children grows up in cities during their critical period of childhood. Therefore, most of them have a strong desire to live and work in the city permanently. They leave rural areas for a long time and the long history of their urban residency has gradually weakened their rural identity. Even for those stay-at-home children, they lure to the city culture and admire the city life. They hold that rural area is backward and look down upon the rural culture.

\subsection{Deficient Social Support}

The development of schools for migrant workers' children is not only influenced by the authority, but also by social environment. Social support is an important external force for school development. The social atmosphere supporting schools for migrant workers' children is indifferent, which hinders school development to some extent. On the one hand, nowadays, the education of migrant workers' children in the mass media is aphasic. It seldom becomes the subject matter in newspapers, magazines, networks and television. It lacks social recognition and is labeled backward. Although in recent years, there are more and more social charitable personage to provide a lot of help for schools. But these help is far from enough. Besides, the vast majority of people hold a negative attitude towards the schools for migrant workers' children. Some people insist that schools for migrant workers' children should be closed. Others believe that the schools for migrant workers' children are "poor schools" and "weak schools". On the other hand, it is difficult to strengthen family-and-school cooperation in schools for migrant workers' children. Most of the stay-at-home children are cared for by their grandparents. Children's parents usually make a living out of the countryside and they are absent in their family education. At the same time, parents don't receive well education, therefore, they can't give their children consistent help in schoolwork. Family-and-school cooperation is difficult to maintain. Under such circumstances, schools for migrant workers' children are under the invisible pressure and faced with the development process. The dilemma becomes even worse than ever.

\section{Countermeasures for School Development}

The education of migrant workers' children has become an urgent problem. Effective measures have to be taken to promote the development of schools for migrant workers.

\subsection{Strengthen Government Support}

Increasing Channels for Raising Funds. It is advisable to set up a funding guarantee system including government funds, social sponsorship and school-self financing. First of all, the county governments actively raise education funds, through the forms of financial allocation, capital increase and land replacement. Secondly, it is necessary for the government to establish local rural education public fund and corporate sponsorship via far-reaching influence of mass media. Therefore, village entrepreneurs, honorary villagers, enterprises and institutions and other social forces have chance to participate in the donation of scholarship. [4] Finally, schools for migrant workers' children should be encouraged to develop school-run enterprises and social services according to their own advantages so as to increase school income and make up for the fund shortage.

Improving the Evaluation and Supervision Mechanism. On the one hand, it is urgent to strengthen the supervision and evaluation of school education. Special and exclusive guidance and supervision should be given to schools to enhance the construction of school-based curriculum so as to promote the development of schools' connotation and characteristics. On the other hand, the government is to innovate the methods of evaluation and explore the independent third party evaluation mechanism in order to promote the school construction.

\subsection{Create Schools Own Characteristics}

The key to the school development is to rely on the schools themselves. Schools of migrant workers' children should learn and be good at seizing the opportunity to make full use of the external advantages to improve themselves. It is necessary for schools to lay emphasis on their own 
connotation construction and teaching quality.

Reshaping Schools' Educational Objectives. Schools for migrant workers' children need to reshape educational objectives and adhere to the principle of individual-orientation. Schools have to lay emphasis on "people's livelihood" as a special positioning. It is desirable that schools appropriately increase the content of vocational education, so that students can work in lines of agriculture, business, crafts, family enterprises and so on, even without entering colleges or universities.

Developing School-based Curriculum. Developing school-based curriculum is an essential way for school independence. Local folk arts and crafts, such as paper-cut, clay sculpture, weaving, wood carving and so on, are encouraged to be introduced into schools. The school needs to strengthen the school-based curriculum. Different measures can be taken into consideration. First of all, it is necessary to make up for the shortage of teacher resources. Teachers are encouraged to go out to learn folk arts from students' parents, farmer technicians and the online class. A team of part-time tutors, such as college student volunteers, local cultural researchers and folk artists' grassroots groups, will be formed to encourage them to enter the classroom and guide the construction and development of school-based curriculum. Secondly, the teaching mode should be innovated with the advantage of small school size. School-based curriculum is set up based on the needs of students and the ability of teachers and the courses are classified into long and short ones. Students are allowed to select courses independently according to their own interests.

Building an Idyllic Campus. Du to the lack of school funds, the construction materials, such as cement and tile, can be replaced with green brick and stone tile. Urban landscape can be replaced with local flowers and trees. In this way, schools not only cut down expenditure, but also create their own character. Fruits and vegetables are to be cultivated on campus plots, which stimulates teachers and students' consciousness of rural culture with special pastoral ecology.

\subsection{Promoting Teaching Staff}

Teachers are indispensable for the school development. There are some measures which could be taken to promote teaching staff. Firstly, public schools are encouraged to play an assistant role in pairing with schools for migrant workers' children. Therefore, a long-term mechanism for the coordinated development of teachers between urban schools and migrant children will be established. Public school teachers, especially teachers of music, art, physical lesson, information and science, are encouraged to "go to the countryside" to teach migrant workers' children. Secondly, it is time to greatly improve teachers' income, including social benefits, through raising funds from the government and other channels. As for the teachers who have made greater contributions will get more pay for the work done. Thirdly, Teachers should be provided with adequate training opportunities for further studies. Forms of training can be adopted multiply and creatively to enhance the pertinence and effectiveness, such as post replacement, network training, sending quality teachers to the countryside, expert guidance, school-based training and so on. Schools for migrant workers' children have to speed up the construction of information technology to enhance the teachers' application ability. High-quality teaching resources, such as distance education and digitalized courses, are to be shared with migrant children's teachers to ensure teaching quality.

\subsection{Establishing a Unified Electronic Enrollment System}

The so-called electronic student status system is a dynamic means of supervision and management for the students' enrollment. [5] The following information can be included, students' basic information, academic performance and transfer reasons. Establishing a nationwide unified electronic enrollment system can improve the nationwide network of student status management and provide continuous services for the children of migrant workers in learning, transfer and promotion.

\subsection{Improving Off-campus Education System}

It is suggested that children's courts for stay-at-home children should be set up in rural areas. The construction of children's palace in rural schools is to be greatly increased. Under the joint efforts 
of village committees, schools and parents, the establishment of "student Village Learning society" and "parents" night school" are to be explored to improve the family education and social education environment.

\section{Summary}

The schools for migrant workers' children have played an active role in the schooling of migrant children. The survival of the school for migrant workers is not confined to the government support. It needs support from all walks of life. The state, society and schools should work together to form a joint force and construct an effective operating mechanism.

\section{Acknowledgement}

The thesis is Ye Chunbo's research findings of the key research project from Social Science Federation of Zhejiang Province in 2017. The research title is School Running Status and Quality Improvement Countermeasures of Schools for Migrant Workers' Children - A Case Study of Ningbo (No. 2017Z09).

\section{References}

[1] $\mathrm{Xu} \mathrm{Li}$, The present situation and countermeasures of schools for migrant workers' children [J]. Modern Education Science (Study of General Education), 2010, (1): 111-112.

[2] Xu Huanwen, Yang Lixia, On the problems and solutions of schools for migrant workers' children in China [J]. Jilin Normal University Journal (Humanities and Social Sciences Edition), 2010, (2): 79-81.

[3] Cai Cheng, Hang Leilei, Education supervision extends to schools for migrant workers' children [J]. Modern Education Science (Primary School Teachers), 2015, (1): 30-32.

[4] Hu Zhongyue, Research on the Operating Mechanism of Schools for Migrant Workers' Children in the New Era [J]. Journal of Zhejiang Normal University (Social Sciences), 2018 (2): 119-124.

[5] Zhao Xiaocui, Research on the current situation, problems and countermeasures of schools for migrant workers' children [J]. Survey of Education, 2013 (06): 8-11. 